\title{
The Extent of the Contribution of the Educational Environment of Najran University in Developing Creative and Innovative Enterprises among the University Students
}

\author{
Ameen Mohammad Nimer (Corresponding author) \\ College of Education, Najran University \\ P.O. Box 1988, Najran 61441, Saudi Arabia \\ Tel: 966-534-238-575_E-mail:nimir_4@hotmail.com
}

Received: May 14, 2016 Accepted: June 16, 2016 Published: June 30, 2016

doi:10.5296/jei.v2i1.9445 URL: http://dx.doi.org/10.5296/jei.v2i1.9445

\begin{abstract}
This study aims at identifying the reality of stimulating educational environment for creativity at the Najran University (NU), and the importance of the availability of certain influencing factors, which in turn contribute to the provision of innovative and creative projects. Reviewing the literature and related studies, the importance of the availability of those factors in the university educational environment were explored and organized into two main categories. The first category: Practices and roles played by the university administration in the development of students to provide creative and innovative projects (6 elements). The second category: practices and roles played by the teaching staff members in the development of students to provide creative and innovative projects (3 elements).A questionnaire consisted of twenty items was designed and distributed a sample of university teaching staff members. The results clarified that such practices and roles were in the moderate level of sample agreement in general, with a decrease in the levels of some elements and slightly higher in others. The results also showed that there were no statistically significant differences due to sex and specialization variables. The study recommended the need to address the shortcomings of each of the following elements. Providing learning resource centers at the university, supporting extracurricular activities 'Students Club', establishing incubators supporting creative projects, providing scientific research centers, establishing scientific and research partnerships, Motivation and encouragement, teaching methods, scientific research, and self-learning skills.
\end{abstract}


Keywords: Stimulating university educational environment, Development of creativity among students, Creative and innovative projects, Najran University (NU)

\section{Introduction}

The rhythms of life in the current era, which characterized by speed, sharp competition, and abundant and complex problems, imposed on the world countries to begin a quick process in all institutions, in terms of restructuring, formulation of their goals and functions to be consistent with this speed and competition, and offer solutions to the problems they face.

Accordingly, the universities had to be at the forefront of these academic institutions. They should have special interest in developing and change, formulating new objects commensurate with the current phase requirements, and taking the initiative and the responsibility of graduating a number of creators and innovators who are able to supplement the National economy by their creativity, coincided with the emergence of new concepts in education as a concept of cognitive economy. "Valuing and recognizing the creativity of our students is one small step towards creating a more creative society: something that ultimately the health of our economy depends" (Jackson, 2008).

Scientists explained such association that the land and money are not the only sources of power. The mind and creativity are the most important factors in increasing the benefit to the capabilities of nations, and the hardness of the economic, social, political and cultural disruption (Hasan, 2004). The world witnesses sharp scientific, technological and economic competition, therefore the future requires a change in the quality of the workforce that universities prepare for the labor market. This labor market does not require just the provision of work force, but needs powers characterized by creativity, and has the ability and high flexibility to respond to all the changes in the global landscape.

\subsection{Problem of Study}

Meanwhile the institutions of the higher education in the developed world have made great strides to achieve the goals of excellence, innovation and the development of the human mind, the universities in the Arab Countries are still far from achieving these goals. On the other hand, the quality of education is also still below the level reached by the universities in the developed countries. Abdulmaksoud (1998) described this situation saying that this reality is a problematic, lacks the possibility of organizing efforts in preparing the creative man. The traditional ways used by these universities hinder the mind capabilities, creativity and the courage to break into the unknown. The Arab education focuses on knowledge and information, and does not take care of creative behavior, abilities and skills. This is due to the old and traditional teaching methods, resources, curricula, organizational structures, and traditional regulators (Hasan, 2004).

The learner should have a different vision about the future, to face its problems and challenges, as the content of education is no longer to understand the past or analyze the present, but to expect the speed of the change and its direction, and should have the ability to see the possible assumptions. Such a trend requires that those in charge of the educational process to develop students' abilities and thinking skills, which in turn help them to provide 
practical solutions for the future (Badran, 2007). Barsons (1971) urged the importance of the social and cultural context in producing creative ideas, when he connected the components, properties and standards of cultural and intellectual heritage with the evolution of scientific creations, pointing to the importance of the role of the regulatory of universities in the growth of creativity and scientific progress.

The challenge for our Arab societies is the inevitable shift to communities that bind science, technology and development. This requires that our schools, universities and all educational institutions turn into farms of human thought, where modern sciences interact with creative education methods, to produce creative minds and effective skills that enable people and state to be in safe of the risk of default and severity of marginalization (Hasan, 2004). Many psychologists assure the importance of addressing the varied and complex life problems by unconventional ways, such as stimulating the creativity of students, development and training them by several methods, which numbered in the United States more than 30 styles and in Japan more than 100. Producing creative products requires creative conditions that encourage and sponsor creativity and creators that contribute to the formation of creative personality and conduct creative processes (Noor, 1998). The progress of any educational environment depends on talent and thinking development of young and old people to be able to think about the phenomena, situations and stimuli that they are exposed without submission or surrender of ideas and ready-made judgments (Alsamarrai, 1994). The issue of creating, discovering and nurturing human talent is a scientific, social and economic issue, needs ideas, techniques and institutions of care and investment (Alzoubi, 2005).

The government of Saudi Arabia offers incorporeal support, human and material potentials for higher education institutions, therefore it is important to study the effects of these efforts on the outputs of the educational institutions, assess their ability to graduate students armed with science, creative and capable of real contribution in create and conduct projects and innovations to solve the problems of the community, and have the ability to contribute to the global production of knowledge and technology. This also requires a study of the obstacles that reduce the students' ability to access the creativity system and provide innovative projects.

This study was to examine the reality of the educational environment of NU, and the extent of its contribution to be a stimulating environment for students to provide creative and innovative projects. This required studying the factors that encourage supporting creativity. By reviewing the theoretical literature and related studies, the importance of the availability of many factors in university educational environment is obvious and could be confined into two main categories:

$>$ Practices and roles played by the university administration in the development of students to provide creative and innovative projects.

$>$ Practices and roles played by the teaching staff members instudent'sdevelopment to provide creative and innovative projects. 


\subsection{Questions of Study}

The study will try to answer the following questions:

What is the contribution of the educational environment of NU in developing students' capacities to provide creative and innovative projects?

Answering this question requires answering the following two questions:

a) What is the reality of the roles and practices carried out by the university administration to develop students' capacities to provide creative and innovative projects?

b) What is the reality of the roles and practices of the teaching staff members to develop students' capacities to provide creative and innovative projects?

Is there a statistically significance due to sex and specialization variables in estimating this reality?

\subsection{Objective of Study}

This study aims to revealing:

1) The extent of the educational environment of NU contributes in developing creativity and innovation among students from a sample of teaching staff members' point of view,

2) The most important elements on which the existence of a stimulating educational environment for creativity and innovation in the academic institution depends; and

3) Uncovering the obstacles that limit students' abilities to access creative and innovative enterprise system.

\subsection{Terminology of Study}

University educational environment: is a micro-society in which members interact, affect each other, which in turn affect the learning outcomes, and this requires the provision of the necessary means and capabilities to have an appropriate atmosphere for students to create (Abu Samra et al., 2004).

Creativity and innovation in educational organizations: the student's ability to produce new, novel and remarkable modules, whether it is an idea, discovery, or invention, so be authentic, modern, and beneficial, lead to the satisfaction of large group of people in a certain period of time (Hasan, 2004). Bulghath (2006) considers it as a human characteristic, reflecting the state of improving mental and mental sublimation, makes human minds more capable to challenge the ordinary.

\section{Methodology}

Descriptive and analytical approach was used to achieve the objectives of study through:

$>$ Reviewing the related literature to address the theoretical framework, interpretation, analysis and design the instrument of study that identified the impact on the educational environment of NU in developing students to provide creative and innovative projects. 
$>$ A questionnaire was designed and judged by a group of experts for validity. The questionnaire stabilized to 40 items distributed on two categories: The first category, practices and roles played by the university administration to develop students' capacities to provide creative and innovative projects. The second category, practices and roles played by faculty members to develop students' capacities to provide creative and innovative projects. To examine the reliability of the instrument, Cronbach's alpha was calculated. It turns out that reliability coefficient $(r=0.884)$. In addition, Likert scale was used to analyze the results of the study, and the questionnaire responses were classified into three levels: 1 to 1.66 (low level), 1.67-2.33 (moderate) level of 2.34 to 3 (high).

Arandom sample consisted of 123 teaching staff members at NU answered the questionnaire.

\section{Literature}

\subsection{University Educational Environment Stimulating Creativity}

University educational environment is a micro-society in which members interact, affect each other, and in turn affect the learning outcomes. This requires the provision of the necessary means and capabilities to have an appropriate atmosphere for students to create (Abu Samra et al., 2004). Generating, disseminating, and employing the knowledge represents the outcome of all the university functions: teaching, scientific research, and community service (Mohammed, 2013). If the various social institutions seeking to achieve the traditional goals passed down through the different generations, the university is required to differentiate from other community organizations to offer a different role in the quality of the goals. This difference is the value added of these objectives, in terms of focus on investment in students' minds and acquire them many skills, which enable them invent and create what develops the economy. "If innovation is the governor element in the quest to possess advanced skills and tools, it should be a strategic goal of creativity in the university for itself." (Obaid, 2004). Soliman (2001) described the creative environment as this social and educational environment that encourages and facilitates the development of talents and creativity. It is unlike the rigid environments that do not allow adventure and risk. The creative environment associated with the educational environment should originate in an educational social environment accompanied by a high state of safe psychological and emotional mood (Eways, 1996). The more able the university to provide an atmosphere characterized by factors and elements contribute to the satisfaction of students; they will have a sense that their goals will be achieved. This will lead to high levels of the learning process, along with increased morale, and a sense of the quality of academic life, which enables them to academic excellence and continue their studies with confidence (Sabo, 1993). This is what might be called the quality of university environment, that is the nature of the academic, regulatory, social and administrative relations prevailing among the members of the university community (Alghanbosi, 2009). Therefore, the university educational environment should turn to 'farms' of human thought, and 'incubators' of creativity and innovation, where modern future-oriented sciences interact with creative methods and technologies of education and learning. Its revenue and outputs will be creative minds, have an effective knowledge-based and authentic skills (Obaid, 2004). 
Eways (1996) and Maayah (2008) said that it is the responsibility of the university to create the environment of creativity for the individuals of the community in general. Therefore, it is expected to provide the elements of creativity within its units and departments, through the revision of its philosophy, mission, policies, strategies, plans, education programs, human cadres and organizational structures. It should make its best to strengthen the ties and relations between itself and the community. The student alone is unable to identify the talent pathways s/he may have, since man has a large number of talents, abilities and tremendous amount of life requirements. This makes the issue of creating, discovering and nurturing human talent a scientific and socio-economic issue, which needs ideas, techniques and institutions of care and investment (Alzoubi, 2005). The outcomes of the university are what constitute the nucleus of the working class community specialized in sciences, in addition to the outcomes of leadership that are able to change ideas of the society about scientific orientation.

Creativity happens through creative a personal behavior that has a variety of mental, active, emotional calm and stable properties, and available outstanding pedagogical, educational, cultural and social care. This is what we can call 'the talent industry and activation of creativity community' (Soliman, 2001). Some studies (e.g. Shehata, 1992) pointed out that students who participate in the activities are characterized by the ability to academic achievement, have a positive outlook towards their colleagues and teachers, the spirit of leadership, and consistency of emotional and positive interaction. They also have more confidence in themselves, and possessing the ability to make decisions, and perseverance in their work. Learning and teaching creativity can occur when there are social and cultural conditions, including educational conditions encouraging and stimulating thinking and creativity. Benet pointed out that thinking can be grown and developed when there are appropriate educational and environmental conditions (Fisher, 1990). Creativity is a psychological experience, an intellectual suffering, and emotional pathos that overcome the limitations and walk in the orbit of freedom. While intellectual planning, which is often reinforced by the dominant culture through valuing the social equilibrium, drives individuals to avoid thinking creatively (Alsharee, 2005). Talent is a dynamic system, consists of specific elements, has inputs, outputs, control, and treatment. The talented person's inputs are the congenital talented properties and the acquired knowledge and skills. The treatment is the operations performed by the talented according to her/his inputs to get the value added outputs. The outputs are the value added. This system is controlled by the capabilities of both of the talented and sponsoring institution to secure the functioning of the system as a whole (Alzoubi, 2005). Thus, creativity in the university system can be accomplished by a complementarity and interactive system consisted of management, employees and organizational structures characterized by creativity and possesses a great deal of flexibility and freedom. In addition, this system should depend on wider use of technology to cope with the demands of the future, and the transition from the traditional methods of teaching to projects that require adding new work and true knowledge-based production. This requires also supplement the student with range of professional and life skills, with an emphasis on extracurricular activity to develop individual and collective talent, and get access to partnerships with factories and institutions working in the field of development, to provide 
technical expertise reflected on students' experience

There are trends regarding programs that achieve excellence and innovation in educational institutions. Some trends emphasize the need to develop clear programs and curricula with certain specifications. While others confirm giving absolute freedom to the privileged and creative learner, while the teacher should be a mentor, guide and observer (Tawfiq, 2005). This requires the full cooperation of all stakeholders in higher education to guide the way and optimized method for building creativity base in university education, through a series of practices. This also requires the need for openness and get benefits from the experiences of developed countries universities, to determine the most appropriate ways to build education based on creativity. In addition, the university can build an educational foundation based on innovation system, if it involves the creative product, i.e. the university student, in the planning process for the construction of this educational base, which based on a culture of innovation, and listen to their views, desires, aspirations and the insatiable needs. It should encourage them to improve their minds and get them to move to process stages in the construction process. Eways (1996) emphasized that to provide a good school environment; two basic elements are required, namely:

Providing satisfaction for all workers in the educational institution, especially the targeted persons of the creative process, i.e. students, to make them feel the sense of security, respect and freedom to study, think and develop creativity and excellence, and their capabilities to self-learning, and self-reliance. This educational institution should encourage learners to express their new ideas without fear of ridicule or defame.

Providing a suitable educational environment to improve the students' achievement, and enable them to access to the creativity and innovation system.

The results of many studies (Alholi, 2009; Alghanbosi ,2009; Alzoubi, 2005; Hasan, 2004) showed that there must be attention to the physical environment at the university, and develop it, and that the educational environment quality includes: the academic, organizational, and social dimensions. These studies assured that there is a close relationship between the availability of such environment and the level of ambition and achievement motivation. The university environment is a fertile environment for the promotion of innovation and development of the university, so it has to have a distinct role in the care, managing and marketing talent. The university should spread the culture of innovation, seek to find creative align with the labor market, and instill knowledge culture that supports freedom and creativity and encourages the producing of knowledge and take advantage of (Mousa \& Al Mariee, 2013). "I see higher education's role as: a) to help people develop as creative individuals because this is the foundation for a more creative society and $b$ ) to provide access to domains, the training necessary to build a creative life in a domain and access to the field of people who are already experts in the domain. In the words higher education has an important role to play in society enabling people to move from personal to cultural creativity" (Jackson,2008)

There are several procedures to spread the culture of innovation and its activities within the university educational environment. The researcher found that innovation system at the 
university can be achieved by two identified categories:

The first category: practices and the roles played by the university administration in the students' development to provide creative and innovative projects.

The second category: practices and roles played by the teaching staff members in students' development to provide creative and innovative projects.

\subsection{First: The Practices and the Roles Played by the University Administration in Students' Development to Provide Creative and Innovative Projects}

After reviewing the studies and references relevant to the study, the researcher found six elements that could contribute well to these practices and roles:

\subsubsection{Providing Learning Source Centers}

Learning source centers are considered the energy for educational and research processes at universities to achieve their objectives (Mahjoub, 2014). The source center is defined as "an independent building supplement of the university, the college or the institute. It includes a variety of sources forms, including printed materials, such as books, dissertations and journals; and unprinted sources, such as audio and video materials, in addition to electronic materials and search engines on the Web. It is managed by qualified and well trained persons capable to provide services to visitors, smoothly and easily." These centers are considered a recent transformation of pattern of the traditional library, which depends mostly on printed sources. These centers also aims at providing students, teaching staff and researchers with sources of knowledge in different patterns to fit all the needs of their visitors. These centers help to develop self-learning, which often leads to develop the cognitive structure of the student who has internal desire to learn. The existence of such internal desire to learn is an indicator of the learner need to search and explore. Some studies (Hijazi, 2001; Mahjoub, 2014) argued that there is an urgent need for a comprehensive source center of education and research, because the creative person needs to involve in a supportive environment. Stuart study (1997) confirmed that the design of the library and learning source centers require a model makes it easier for students to take advantage of all available sources, especially the idea of self-service.

\subsubsection{Supporting Extracurricular Activities (Student Clubs)}

Humans differ in skills and talents they have. Humans are born with these skills and talents, or they can learn them. These skills and talents can be known, or may be static rigid, have had no chance to be known and discovered. The talents and skills possessed by an individual are indicators of ingenuity and innovation, since they have multiple features: physical, mental and technical. Student clubs at the university can be an appropriate place to express the inner potentials of human beings, and a fertile area for the discovery of the self, because they represent the extracurricular activity in the university educational environment. Students often visit these clubs for entertainment and getting out of academic atmosphere, because they are not subject to evaluation. Student clubs provide a fertile environment for unloading students' energies and talents. The student clubs activities are varied: they may be athletic, 
artistic, literary, or scientific, and they lead to the development of social, mental, and manual skills that can hardly be acquired by curricula that are not based on the activity (Mechling \& Oliver, 1983). Student clubs can be considered a fertile place to monitor the phenomena that exceed the normal description of their visitors, if they running by dedicated administrative staff who use their experiences to detect and guide the creative and talented students, and refine their physical, intellectual, literary, artistic and mental creations. "The talented university can develop talent among students and then converts it into useful values." (Alzoubi, 2005). Qutb's (2006) study showed that the student activities effectively and directly contribute to the contemporary educational systems in the formation of student personality, refining her/his capabilities, developing skills, launching creations, and mental, social, cultural, physical, technical, scientific, psychological and technical expressions. The most prominent result of that study is that there is a strong relationship between student activities at the university and the ability to detect aspects of tendencies and creativity among students. It reported also that the student activities, which are distributed through student clubs, contribute to build a positive atmosphere at the university, and achieve the merge between theory and practice, especially in the practice of scientific and sports activities.

\subsubsection{Establishing Incubators Supporting Creative Projects}

Scientific creativity incubators at universities are an integrated system, considers any small project as 'newborn' baby requires intensive care and overall interest. Therefore, she/he needs an incubator to protect her/him from the dangers that surround her/him, provide continuing energy to be eligible for the future, and equipped with success mechanisms (Mohammed, 2013). It is also known as "development institution working to encourage and support the young people who have creative ideas, but do not have the financial resources or global experience to achieve their projects and ideas. During staying at the incubator, the client is provided by advisory, technical, administrative, productive, marketing and financial, and legal services, until the founding of the company and perhaps the start of production and the actual work (Muhammad, 2013). Almazeedi and Alkhadra (2000) defined the incubator as an advanced base, which is able to provide services that will develop and improve the chances of success of new business projects and ensure success through the critical periods, often the first two or three years. Establishing incubators within the university is important because they are fertile scientific environment contain all ingredients, diversity of disciplines, and provide research incentives for both university students and teaching staff members, which lead to the tangle and mixing produce new knowledge. The findings and recommendations of many studies (Abdulwahab, 2011; Mohammed, 2013; Saleh, 2006; Obaid, 2004; Almazeedi \& Alkhadra, 2000) state that the Arab Universities should follow the Global Universities in creating technology incubators to receive technological pioneering ideas. These incubators should be as science 'parks' and as a means to transform innovations into economic fortunes. To be centers of creativity and excellence where students can practice their interests, inside and outside the university. Every university should dedicate part of its territory for establishing a research incubator to help companies and institutions productivity. Mohammed (2013) added that this incubator should not be limited to scientific research incubators, but also to humanitarian and educational aspects, concerned with the development of human 
thought. Abdulwahab (2011) emphasized the importance of working on the launch of projects and initiatives in the field of scientific innovations at university educational environment, and encouraging students to join. Almazeedi and Alkhadra (2000) stated that technological incubators significantly contribute to the development of creative projects, create new jobs, lead to successful technological projects, and work as a link between the activities and the results of research, research centers, national industries and institutions of higher education.

From international experiences in this field: American experiment known as creative business incubators, which serve as incubators for ideas and creative talent, consist of an integrated system of services, supportive facilities and consultative mechanisms, deal with small projects and ideas and creative talent to be able later to move to global labor markets. They are usually inside campus, or in a center of $\mathrm{R} \& \mathrm{D}$ centers of the university (Wisconsin Department of Commerce, 2003).

\subsubsection{Providing Scientific Research Centers}

Scientific and cognitive progress and the use of scientific research in the development and improvement of technical methods in any country can make industrially and socially advanced. This justifies the argument, "the modern force linked to human capital sources than natural wealth", it is the force of innovation and invention (Jerio, 1988). Universities must seek to develop specialized research centers to meet part of the needs of society in general, and the region where there are in particular, and work to find a suitable mechanism ensures the employment of the results of scientific research for development, and community service. Bulghath (2006) and Abdulwahab (2011) pointed out the importance of reforming the system of scientific research at universities. It requires a set of practices, which can lead to correct creative research path at universities, transform it into research institutions, give more attention to preparing skilled researchers, develop a set of laws and regulations governing the activities of scientific research, pursuit of providing government support, and improve the living conditions of workers in scientific research and production, of the distinctive international experiences in this field: the Canadian Centers of Excellence experience, that form a strong partnership between universities and productive enterprises. These centers exist within universities to document the relationship between universities and industry in Canada (Maayah, 2008). Results of Mohammed's (2004) study showed that scientific research, characterized by creativity and innovation, ensures a high level of efficiency that can achieve a competitive advantage. This requires establishing and supporting research centers specialized in developing the priority areas of development, related to industry and innovation(Mousa \& Al Mariee, 2013).

\subsubsection{Establishing Educational and Research Partnerships}

The joint cooperation between the university and the sectors of production and services, whether research, training, joint ventures or exchange of experiences, offers many positives in establishing university educational environment that supports creativity. This links the university closely to the development of society; increasing university efficiency, and availability of additional funding sources that offer opportunities to pursue basic and applied modern research, provide solutions to the problems of the community, and access to scientific 
and technical knowledge and future trends (Maayah, 2008). The partnership between universities and the productive enterprises can be established on the basis of cooperation and achieving a lot of common interests between the two parties: exchange financial support for research advisory services; active and direct participation in developing, innovating and creating of technical expertise and development; research related to work market to help resolve productivity problems facing industrial production and service sector; and expand the continuing education and training programs (Albayati, 2007). Maayah's (2008) study highlighted four international experiences in the field of partnership between universities and production institutions as models of partnership. 1) American experience (creative business incubators), 2) Canadian experience (centers of excellence), 3) Japanese experience (Joint research), and 4) British experience (universities of industry). This confirms what indicated by Hasan (2004) about the need of scholarship for students and the teaching staff members to the advanced countries in the field of university education to take advantage of such experiences and transport them to the education system in the region. Creativity at university education can also be achieved through the promotion of it in the different stages of public education, then submit it for university education, through an organic link that allows the university to play a new role towards public education that contributes to its progress and development, rather than just observes critique (Eways, 1996).

\subsubsection{Motivating and Encouragement}

Motivating and encouragement in educational systems are the key factors in getting a positive impact of any needed action. They are natural extension of general human behavior that likes praise and honor. They drive people to make their best and greater efforts in order to gain a competitive advantage. Motivation and encouragement at the university educational environment means the mechanism and methodology followed by the university administration to stimulate students' creativity, materially and morally. This can be achieved by establishing a set of legislations, regulations and laws for creativity business. The aim of such procedures is to move from the randomness and blur to the organized system of this material and moral support.

\subsection{Second: The Practices and Roles Played by the Teaching Staff Members in Students' Development to Provide Creative and Innovative Projects}

The positive interactive educational environment helps in establishing a creative environment that allows the transfer of creative thinking, which is a reciprocal relationship between the student and educational environment. This environment is linked to a variety of stimuli and interactions between the students themselves, and its processes and procedures and makes an impact on the formation of the trend that is reflected on the satisfaction of students and their motivation with learning (Mcrobbie \& Fraser, 1993). Alatari (1997) pointed out that there is a strong relationship between academic excellence and educational environment. The traditional education systems adopt that type of evaluation that classifies students in the classroom by judging the student as an intelligent or non-intelligent, i.e. rely on a stratified mental capacity. However, evaluation system must depend upon "the existence of an intelligent curriculum, or non-intelligent. There is an education and evaluation methodology 
that encourages intelligence and creativity, and a methodology that suppresses or extinguishes them" (Obaid, 2004). The main problem with traditional higher education as a vehicle for preparing learners for the complexities of the world ahead of them is that it seems to take such a narrow view of what learning and knowledge is. Higher education is pre-occupied with codified knowledge and with its utilization by learners in abstract hypothetical problem solving. This is not to say that handling complex information in this way is not useful - far from it: it is an essential process for enabling students to learn how to think. (Jackson, 2015)

Accordingly, the teaching staff's behavior at the university should be changed to become more convenient with the requirements of constructing the creative system at the university, to be more participatory with the student who carries out a bigger bulk of search for knowledge with supervision of the teaching staff members. These changes include three main directions: teaching methods, scientific research, and self-learning.

\subsubsection{Teaching Methods}

Badran, (2007) Pointed to the importance of the development of curricula and teaching methods, and our understanding of the educational system itself, where the university education system in the Arab world based on 'rote and recall', which is contrary to creativity. The reasons of weakness of creativity at the university educational environment are (Ibrahim, 2008; Alsharee, 2005; Noor, 1998): excessive focus on the available information, which requires taught mostly by a methodology based on rote and recall, failure to address knowledge that requires research and investigation. Herein lies the paradox between the reliance on narration and the culture of memory, lectures and conducting pre-prepared experiments, and the reliance on the different methods of thinking, which produces new knowledge, and pays attention to ideas and provides alternatives, and the continuous interaction with technology era. If we want to support the development of learners as thinkers who can integrate their analytical and creative thinking and action in the manner caricatured, then we need to understand the epistemology that connects learning and practice (using the idea that practice is about people working on purposeful activity to achieve their goals regardless of whether they are studying or in a job) (Jackson, 2015). The learning environment must give way for students to find solutions to the problems rather than providing ready-made ones, adoption programs facilitate the creativity among university students through training on a number of skills in ways of thinking (Baillie, 2010).

The teacher is the main component in conducting the educational room through a set of steps to create effective learning, provoke the minds and open perceptions. When the teaching staff member gives the student an active investigative role in the leadership of a research or laboratory work, and gives them the opportunity to discover things for themselves, s/he enhances and reinforces the creative environment (Ying, 2008). Education associated with the laboratory creates an effective learning environment, and gain practical experience that will allow the exercise of the real work, because the information and facts that student acquires during studying, with no practice, remain worthless abstract ideas (Badran, 2007). Creativity in teaching is the best way to do the job of university education by focusing on the mental and cognitive environment of the student, and the development of her/his thinking and 
training her/him on dialogue. This cannot be achieved, but through the diversification of teaching methods, and away from the ways in which the student does not react, as lecture (Alshadouh, 2012). Chung (1991) stated that structuralism is an approach encourages creative environment in the learning environment, where knowledge is shared between the teaching staff member and the student. This approach focuses on problem-solving skills, higher systematic thinking and deep understanding, as well as encourages cooperation and partnership between learners. These skills support the creative atmosphere of the learners. The student should possess high-level mental mechanisms that contribute to manage her/his thinking in accordance with the creative approach. That approach enables her/him to discover the reality of the events, react boldly, without fear or hesitation, to technical innovations, and explore the new scientific discoveries consciously that lead to more modern and contemporary discoveries (Ibrahim, 2008). Many studies (Bulghath, 2006; Hasan, 2004; Obaid, 2004) stated the importance of the revision of the curricula, by developing and modifying them, creating creative and innovative applications, transforming from 'rote and recall' to thinking methods and developing awareness, and effective employment of technology in developing curricula content and methods of university teaching.

\subsubsection{Scientific Research}

Actual employment of scientific research in the educational process is an essential feature of effective teacher. The effective functioning of the capabilities and skills of scientific research student within the institution leads to make both of them distinguished (Mohammed, 2004). Reliance on scientific research, as a source of supporting the educational process, requires a set of steps: 1) Training students to gain research skills. 2) Distributing the course topics to the students from the beginning of the semester. 3) Presenting samples of published scientific research in international journals. 4) Following up preparation of scientific research stages. 5) Student presents the most important findings in her/his research in front of colleagues. 6) Telling students the assessment of her/his research according to pre-defined and published standards.

\subsubsection{Self-Learning Skill}

The self-learning skill is one of the configuration requirements to enter the innovation system in higher education, where the major task of the teacher in the developed countries has become guiding the learner to learn by her/himself, including setting objectives, how to get the information, and the ability to self-assessment (Hassan et al., 1998). This is what Mcglynn (2001) highlighted when talking about 'self-regulation' as a kind of learning gives a stimulus for students, affect their level of achievement, and contribute to the revitalization of their mental abilities. Therefore, it is important to provide students the concept of self-learning: how to learn, how to remember, how to think and how their motivation is stirred for themselves. Schunk (1998) and Zimmerman (2002) confirmed that self-regulation helps to develop learning skills for life, which is one of the most important educational goals. This requires helping students to use the self-organized learning strategies. This is supported by structuralism, where its supporters believe that the true knowledge is built by the learners themselves in the context of their current knowledge, which is based on previous experiences 
(Jonassen, 1994).

\section{Results Discussion of Explanation}

4.1 The First Question: What is the Contribution of the Educational Environment of NU in Developing Students' Capacities to Provide Creative and Innovative Projects?

To answer this question, means and standard deviations were extracted for the first and second category as follows: First, the mean of each item of each category separately. Second, the mean of the items of each element of category separately. Third, the mean of the total items of category. Answering the first question requires answering each of the following two questions:

4.1.1 What is the reality of the roles and practices carried out by the university administration to develop students' capacities to provide creative and innovative projects?

Table 1 . The statistical analysis of the first category

\begin{tabular}{|l|l|l|l|}
\hline Elements of the first category & $\mathrm{M}$ & $\mathrm{SD}$ & Level \\
\hline learning source centres & 1.88 & 0.439 & moderate \\
\hline extracurricular activities (student clubs) & 1.44 & 0.169 & low \\
\hline incubators supporting creative projects & 1.47 & 0.355 & low \\
\hline scientific research centres & 1.79 & 0.175 & moderate \\
\hline scientific and research partnerships & 1.56 & 0.286 & low \\
\hline motivating and encouragement & 1.78 & 0.070 & moderate \\
\hline Total & 1.64 & 0.296 & low \\
\hline
\end{tabular}

The result of the first category items 'The practices and the roles played by the university in the development of students to provide creative and innovative projects' was weak. The mean was 1.64 and the standard deviation was 0.29585 . The elements of the first category were: 1 ) learning source centres, 2) extracurricular activities (student clubs), 3) incubators supporting creative projects, 4) scientific research centres, 5) scientific and research centers, and 6) motivating and encouraging educational partnerships.

The first element of this category 'learning source centers' has 'moderate' level of respondents' agreement $(\mathrm{M}=1.88 ; \mathrm{SD}=0.439)$, meaning that $\mathrm{NU}$ administration cares about these centers moderately. This level of respondents' agreement may due to several reasons. 1) 
These centers are limited to the general NU library. There is not a learning resource in every college and faculty to fulfill its specific specialization. 2) These source centers are undiversified; they do not include audio-visual materials, but only printed ones. 3) These centers have not enough motivational atmosphere for students to attend, the working hours are limited, and there are no service-facilities. This result consents with Stuart (1997) who emphasized that the library design that does not facilitate taking advantages of its available possibilities, particularly activating the idea of self-service, is a main reason to avoid attending. 4) The quality of the staff managing the learning source centers and their competence in managing and activating these centers, through awareness of their importance and facilities, or by providing programs that help students to get the most benefits of them. This is confirmed by Mahjoub (2014) when stated that the greatest benefits of learning source centers depend on the availability of qualified and trained staff that supervise the provision of services for their visitors. 5) Lack of awareness of the existence of electronic learning sources by UN, containing Arabic and English databases and digital library. This shortcoming hinders the achievement of maximum advantage of them. This is consistent with Mahjoub (2014) that the lack of awareness of the existence of electronic sources of information led to the limited access to digital library services provided by learning source centers, while the current study indicated that a high percentage of the teaching staff members and students tend to get information largely from the internet.

The second element of this category 'extracurricular activities (student clubs)' has 'low' level of respondents' agreement $(\mathrm{M}=1.44 ; \mathrm{SD}=0.169)$. Analyzing this element showed that there is a defect in the promotion of student activities. While the Dean of Student Affairs at UN, as advertised on the front page of the University website, believes that it takes care of activities and programs that allow students the opportunity to acquire knowledge, experience and skills that qualify them for the post players inside and outside the university, the students do not intuit this interest for several reasons. 1) these activities are not implemented through student clubs which have scientific, cultural, sports and technical aspects giving them the opportunity to express their inner interests, and be fertile ground to discover themselves, their talents, potentials and launch creativity and their mental, social, cultural, physical, technical, scientific, psychological and technical skills and expressions. The NU efforts in such activities remain randomly and disorderly, which reduce the chances to discover students' talents and establishing a creative environment. Qutb's (2006) study proved that there is a strong relationship between the organized activities at the university and the ability to detect aspects of tendencies and creativity among students, and contribute to establishing a positive atmosphere at the university. 2) The quality of the Deanship of Student Affairs staff may be not specialized in running such activities. They have limited experience in building multi-organization activities. There is no department for student clubs or student councils can play a major role in its management. 3) Unfinished infrastructure of the university, the long distance between the NU and downtown reduces the chances students to stay for long periods of time that can allow participating in the evening activities.

The third element of the first category 'incubators supporting creative projects' have 'weak' degree of respondents' agreement $(\mathrm{M}=1.47$; $\mathrm{SD}=0.355)$. Although NU established an 
incubator named 'promising center for electronic sensors', and appointed a number of $\mathrm{PhD}$ researchers, its impact has not been reflected on the university students. That may be due to: 1) It seems that the nature of work in this incubator is not available for the university students. It is limited to its workers and to some specific research disciplines. 2) The weak relationship between this incubator and the industrial centers leads to low reputation of it. This result agrees with Abdulwahab (2011) point of view that the weakness of knowledge producing organizations in providing creative projects leads to inability to attract the attention of the industrial enterprises. 3) Poor communication between the incubator and creative students and their teachers may be due to the shortage of the teaching staff members' interest in discovering creative students and encouraging them to communicate with this incubator. 4) Failure to launch innovative projects to students sponsored by such incubator reduces the motivating factors of students. This result agrees with the perspective of Abdulwahab (2011) and Mohammed (2013) that the lack of projects and initiatives launched in the field of scientific innovation in the educational environment reduces the motivation aspects of the students to join. 5) The lack of expansion in research incubators at the university to include humanitarian and educational aspects reduces the chances of the diversity of the manifestations of creativity among students and taking into account their interests. This result is consistent with Mohammed study (2013).

The fourth element of the first category 'scientific research centers' has 'moderate' level of respondents' agreement $(\mathrm{M}=1.79 ; \mathrm{SD}=0.175)$. Although $\mathrm{NU}$ has provided five research centers, equipped with high-level laboratories and devices, especially in the medical and science faculties, the response to this element items was moderately, which means that these centers are not working efficiently, and need more attention to play their real roles. The reasons for that may due to several reasons: 1)The lack of motivation of students to do quality research and can be ascribed to a lack of encouragement and monitoring the teaching staff members. 2)The lack of students' awareness of the existence of such-equipped research centers, which can help them in the provision of advice and support. 3) Most of teaching methods at the university rely on the theoretical aspects without integrated practical aspects, which reduces the opportunity for the creation of genuine scientific research, which also helps in activating the role of these research centers. The researcher believes that the lack of exercising laboratory work reduces the chances of experimentation, testing and discovery, which leads to weaken of creativity and innovation aspects among university students, and devote an idea to rely on theoretical information. It appears that the teaching staff members do not guide their students in using such devices and instruments. There is no research partnerships with interested students in certain aspects, which helps them in the future to adopt an independent research projects. This result consented to Almalkawi (2013) and Ricardo (2003).

The fifth element of the first category 'scientific and research partnerships' has weak degree of respondents' agreement $(\mathrm{M}=1.56 ; \mathrm{SD}=0.286)$. The NU offers a lot of scholarships to its students with many international universities in various disciplines. However, this scholarship does not appear dramatically, because the majority of students have not finished studying abroad, perhaps because the NU is considered new compared with other Saudi universities. 


\section{Ml Macrothink}

The researcher explains this result by some reasons: 1) The lack of partnerships with international advanced global ranked universities that can support the educational and research programs. 2) The lack of convergence of scientific delegations from international universities to visit UN, meet students, provide scientific and research advice and offer creative ideas. 3) Low level of partnership with national supportive companies financially and morally, interested in research and development. 4) Low level of partnership with the public education sector through an organic link that allows the university to play a new role in public education, contributing to the progress and development rather than just observation and criticism. This analysis is consistent with Saleh (2006), Maayah (2008) and Eways (1996).

The sixth element of the first category 'motivating and encouragement' has medium degree of respondents' agreement $(\mathrm{M}=1.78 ; \mathrm{SD}=0.07)$. This level of agreement shows that NU administration motivates and encourages students' creativity by honoring creative students financially and morally, displaying various creative students' works in local and foreign scientific forums, and clearly by participating in the established student conferences at the level of the Saudi universities seven years ago. It should be noted, however, that there might be deficiencies: 1) in legislation and regulation to help organize the creative process of university students. 2) There is weak awareness of the importance of creative works and their future revenues. 3) The university does not have an office to receive creative ideas of students. Such office aims at receiving students' ideas, and offers them to supportive agencies. It is clear that lack of encouragement, motivation, supporting and honoring reduce innovation development opportunities among university students, creating a spirit of competition, and in return the higher of the material and moral stimulus, the higher positive feedback. This result is consistent with the results of Hasan (2004), Alzoubi (2005) and Bulghath (2006) studies.

4.1.2 What is the Reality of the Roles and Practices of the Teaching Staff Members to Develop Students' Capacities to Provide Creative and Innovative Projects?

Table 2. Statistical analysis of the second category

\begin{tabular}{|l|l|l|l|}
\hline Elements of the second category & $\mathrm{M}$ & $\mathrm{SD}$ & Level \\
\hline Teaching methods & 2.35 & 0.586 & medium \\
\hline Scientific research & 2.03 & 0.186 & medium \\
\hline Self-learning skill & 2.40 & 0.268 & medium \\
\hline Total & 2.24 & 0.415 & Medium \\
\hline
\end{tabular}

The result of the second category items 'The roles and practices of the teaching staff 


\section{MInstitute Macrothink $_{\text {Int }}^{\text {Intis }}$}

members to develop students' capacities to provide creative and innovative projects' was medium. The mean was 2.24 and the standard deviation was 0.41526 . The elements of the second category were: 1) teaching methods, 2) Scientific research, and 3) Self-learning skill.

The first element of this category 'teaching methods' has 'medium degree of respondents' agreement $(\mathrm{M}=2.35 ; \mathrm{SD}=0.586)$. This result means that the teaching staff members' roles were in good condition, but has not reached the high level that can make noticeable progress in the development of creativity among students. The reasons of this weakness may be: 1) The focus of university education is on providing information in traditional methods, without a pivotal role of students to discover, formulate or present in a new knowledge-based template. This type of teaching leads to some kind of stalemate, because it reduces the chance to search for knowledge, investigate the concepts, verify credibility, and use functionally. This result matches the results of Ibrahim (2008), Alsharee (2005) and Noor (1998) studies. 2) The weak reinforcement of thinking approach, especially critical thinking, that enables students to accept any facts when only there are the concrete are proof and evidence, leading to enhancing usage of the scientific method. The lack of practicing this kind of approaches within the educational context, leads to weaken the spirit of creativity among students. This is compatible with Baillie's (2010) study. 3) The teaching staff members provide scientific materials without monitoring the phenomena of creativity their students may have, or establishing scientific partnership that may result in an innovative work in the future.

The second element of this category 'scientific research' has a medium degree of respondents' agreement $(\mathrm{M}=2.03 ; \mathrm{SD}=0.186)$. This result means that there are practices and roles for the development of scientific research skills of students but they were not in the required level. Many reasons can be mentioned: 1) There are a number of the teaching staff members do not employ scientific research in their courses. They are content with the information and knowledge they already have, and just provide them to students using the traditional lectures. This result varies with the findings of Mohammed's (2004) study. 2) The research themes that are required from students may not belong to the curriculum contents. Students are asked to make a research just to have a complementary score. 3) Following up the stages of research preparation by the teaching staff members during the given period is weak. 4) The lack of pre-defined set of criteria declared to the students to assess the quality of scientific research provided by them. 5) There is no long-term research partnership between the teaching staff members and students, that reduces opportunities for creativity, while this partnership enhances the chances of promotion of the manifestations of creativity among students. This vision is consistent with the results of Mohammed (2004).

The third element of this category 'self-learning skill' has also 'medium degree' level of respondents' agreement $(\mathrm{M}=2.40 ; \mathrm{SD}=0.268)$. It appears to the researcher that there is interest in this element, but it is not enough. It shows that there is an interest in the subject of self-learning among the teaching staff members as a skill that should be acquired by the university students. However, the practice has not reached an advanced stage in supporting its requirements, and that it is not influential enough for students to be creative and able to discover themselves and their talents. The researcher attributed the reasons for this shortcoming for a variety of reasons: 1) There may be a weakness of some the teaching staff 
members on how to train students on self-learning skill, that reduces chances of assisting students to use the self-organized learning strategies. 2) Non-specified hours allocated for self-learning practices calculated from the teaching plan to support creations of students. 3) The lack of encouraging and motivating students spend enough time in the learning source centers. 4) The lack of activities that support self-learning skills, such as scientific trips, or scientific laboratories that enable students acquireself-experience. This result is consistent with Schunk (1998), Mcglynn (2001) and Zimmerman (2002).

\subsubsection{Statistical Analysis of Both Categories}

Table 3. Statistical analysis of both categories

\begin{tabular}{|l|l|l|l|}
\hline Category & $\mathrm{M}$ & $\mathrm{SD}$ & Level \\
\hline $\begin{array}{l}\text { The first category: roles and practices carried out by the university } \\
\text { administration to develop students' capacities to provide creative and } \\
\text { innovative projects }\end{array}$ & 1.64 & 0.296 & Weak \\
\hline $\begin{array}{l}\text { The second category: roles and practices of the teaching staff } \\
\text { members to develop students' capacities to provide creative and } \\
\text { innovative projects }\end{array}$ & 2.24 & 0.415 & Medium \\
\hline Total & 1.94 & 0.450 & Medium \\
\hline
\end{tabular}

The mean of the two categories is (1.94) and the standard deviation is (0.45). This result means that the contributing of the educational environment and the practices and roles, of both the university administration and teaching staff members, in developing the creative and innovative enterprises among Najran students was medium. However, this contribution is not enough to achieve students' creative projects. The researcher discussed causes of such result for each category.

4.2 The Second Question: Is There a Statistically Significance Ascribed to Sex and Specialization Variables in Estimating This Reality?

4.2.1 Statistical Analysis of the Sex Variable 
Table 4. Statistical analysis of the sex variable

\begin{tabular}{|l|l|l|l|l|l|l|l|}
\hline Category & Gender & $\mathrm{N}$ & $\mathrm{M}$ & $\mathrm{SD}$ & $\mathrm{DF}$ & $\mathrm{T}$ & Sig. \\
\hline $\begin{array}{l}\text { The first category: roles and practices } \\
\text { carried out by the university administration } \\
\text { to develop students' capacities to provide } \\
\text { creative and innovative projects }\end{array}$ & Male & 60 & 1.59 & 0.323 & 121 & & \\
\cline { 2 - 9 } & Female & 63 & 1.68 & 0.269 & 121 & $-.901-$ & .373 \\
\hline $\begin{array}{l}\text { The second category: roles and practices of } \\
\text { the teaching staff members to develop } \\
\text { students' capacities to provide creative and } \\
\text { innovative projects }\end{array}$ & Male & 60 & 1.70 & 0.323 & 121 & & \\
\cline { 2 - 8 } & Female & 63 & 1.78 & 0.269 & 121 & $-.901-$ & .385 \\
\hline
\end{tabular}

The result showed that there is no statistically significant indication ascribed to the sex variable. This means that there is an agreement and convergence of views about roles of the university in developing creative and innovative enterprises among students (the first category). This may be ascribed to the administration of NU is one administration for both male and female, so it is natural to find this matching of their perspectives towards roles and practices carried out by the University in this regard. There is no statistically significant indication in the second category either. It can be inferred that the practices and roles of the teaching staff members of both sexes are similar. The lack of awareness of the importance of building an innovation system was the cause of this weakness.

\subsubsection{Statistical Analysis of the Specialization Variable}

Table 5. Statistical analysis of the specialization variable

\begin{tabular}{|c|c|c|c|c|c|c|c|}
\hline Category & College & $\mathrm{N}$ & M & SD & DF & $\mathrm{t}$ & Sig. \\
\hline \multirow{2}{*}{$\begin{array}{l}\text { The first category: roles and practices } \\
\text { carried out by the university } \\
\text { administration to develop students' } \\
\text { capacities to provide creative and } \\
\text { innovative projects }\end{array}$} & Scientific & 60 & 1.7000 & .30943 & 121 & \multirow[t]{2}{*}{1.338} & \multirow[t]{2}{*}{.189} \\
\hline & Literary & 63 & 1.5775 & .27457 & 121 & & \\
\hline \multirow{2}{*}{$\begin{array}{l}\text { The second category: roles and practices } \\
\text { of the teaching staff members to develop } \\
\text { students' capacities to provide creative } \\
\text { and innovative projects }\end{array}$} & Scientific & 60 & 2.2832 & .38478 & 121 & \multirow[t]{2}{*}{.677} & \multirow[t]{2}{*}{.509} \\
\hline & Literary & 63 & 2.1947 & .45053 & 121 & & \\
\hline
\end{tabular}


The result showed that there is no statistically significant indication ascribed to the variable of specialization. This means that the practices of the teaching staff members of both scientific and literary disciplines were similar.

While it is assumed that the scientific faculties are more interested in the development of creativity among students, because they provide practical and applied innovation more than theoretical courses, and equipped with laboratories and devices that allow the application of learning outcomes, this interest is apparently limited to the teaching staff. As for the teaching staff members of the literal faculties, they feel that their efforts are limited to the transfer of knowledge to students traditionally through lectures. This reduces the chances of creating a spirit of creativity among students in building an innovative system to help them in providing innovative and creative solutions to many problems facing their communities.

\section{Conclusion}

Establishing an innovation system in the educational environment depends on the availability of a range of factors, which in turn contributes to the promotion of opportunities for creative and innovative projects of students in all the different aspects of life. In this study, the reality of the educational environment was studied through two main categories. The first: practices and the roles played by the university administration in the student development to provide creative and innovative projects, according to six elements: 1) learning source centres, 2) extracurricular activities (student clubs), 3) incubators supporting creative projects, 4) scientific research centres, 5) scientific and research partnerships, and 6) motivating and encouragement. The second category: the practices and roles played by the teaching staff members in the development of students to provide creative and innovative projects, according to three elements: 1) teaching methods, 2) Scientific research, and 3) Self-learning skill. The results of study concluded that reality of the educational environment in the development of establishing creative and innovative projects has a medium degree. There is no statistically significant indication ascribed to the variable of sex or specialization. These results show that there are roles and practices, but they are not effective and influential enough. The lack of creative and innovative projects advertised among university students is the obvious proof. This requires, from the researcher's perspective, to have a great interest in each of the elements, study based upon, and recommend the following actions. The university needs more focus to establish learning sources centers, designed along the latest methods and techniques, include audible, legible, visible and electronic sources in each faculty. These learning resources are necessary to help university students to get extensive and deep knowledge. This also requires the creation of a motivational atmosphere frequenting these centers, providing them with facilities and support services that allow continuity for long hours. It is important to increase the work hours, and provide qualified trained staff to implement programs that promoting the opportunities to take advantages of them, and attract students to attend. In terms of the extracurricular activities, it requires the university to strengthen these aspects and regulating through the establishment of multi-scientific, artistic, cultural and sports student clubs supervised the university administration and the students themselves. As for the element of scientific incubators, the NU must play a major role in the establishment of incubators in various disciplines, to receive the entrepreneurial ideas, and be 
centers of creativity and excellence in which students practice their interests, not limited to teaching staff members. These incubators should establish partnerships with students and cooperate with productivity companies and institutions that may provide financial and technical support. The task of those incubators is to announce scientific innovative projects and initiatives and encourage students to access them. These research incubators should be expanded to include humanitarian aspects as an effort to provide innovative ideas to deal with the problems afflicting society. As for the element of the research centers, it is required to repair these centers system and reform their status, to play a pivotal role in spreading the scientific research culture among students. These centers should organize research partnerships between students and teaching staff members, and be linked to industry, development and innovation. It is also required to establish local and international educational partnerships to achieve the concept of a knowledge-based economy, through partnerships with prestigious international universities, reception of scientific delegations from those universities to achieve scientific exchange, in addition to partnerships with national companies and public education sector. For the teaching methods used by the teaching staff members, they must shift from the traditional framework to a more scientific and practical practices, and rely on programs facilitating the creativity among university students through training on a range of skills that promote creative and critical thinking. For the development of scientific research, it would require the deployment of a culture of scientific research by the teaching staff members, and adoption of scientific activity in their courses, with the importance of being linked to them. The students' researches must be subject to constant follow-up and evaluation by the teaching staff member. In terms of the development of self-learning skills, it is recommended to allocate specific hours of study plan to support self-learning skills, external scientific activities such as scientific visits and trips, strengthen self-reading and guide students to the learning source centers to acquire these skills.

\section{Acknowledgements}

The research is financed by the Deanship of the Scientific Research at Najran University (NU/SHED/14/123).

\section{References}

Abdulmaqsoud, M. F. (1998). Obstacles of the development of creativity in the Arab education and ways to address them: An analytical study (Year 15, No. 48, pp. 4-49). Al-Tarabiyah Almuasira, Egypt.

Abdulwahab, J. A. (2011). The context of scientific innovation and building a cognitive society: A field study of the perceptions of Arab academics at Sultan Qaboos University (Yearbook 31. 335. pp. 8-190). Hawliyat Al-Adabwalolum Al-Ijtimaia, Kuwait.

Abu Samra, M. A., Imran, M., \& Titi, M. A. I. (2004). University environment in the West Bank universities in Palestine and its relationship to the level of ambition among students (No. 44, pp. 197-236). Majalatitihad Al-Jamiat Al-Arabia, Jordan.

Albayati, Y. K. (2007). Educational philosophy, university environment and funding - Gates 
to stimulate scientific research in the Gulf universities (No. 36, pp. 70-76). Ara' Hawla Al-Khaleej, UAE.

Alghanbosi, S. B. S. (2009). The quality of university environment in some colleges at Sultan Qaboos University from the perspective of students (Vol. 12, No, 25.pp, 89-120). Altarbia, Egypt.

Alholi, A. A. (2009). Evaluation of the quality of university environment from the viewpoint of the graduates of the Islamic University of Gaza (Vol. 17. pp. 45-79). Palestine.

Almazeedi, S. M., \& Alkhadra, W. F. (2000). The role of technology incubators in the creative development of enterprises (pp. 2-13). Sixteenth Annual Scientific Conference (small projects and prospects for sustainable development in the Arab world). Egypt.

Alsamarrai, M. S. (1994). Creative thinking among Faculties of Educational Science students (Vol. 14, No. 1, pp. 188-204). Almajalla Al-Arabiyahlil-Tarbiyah, Tunisia.

Alshadouh, W. M. (2012). The degree of satisfaction of Jerash University students of the university environment (No. 61, pp. 281-303). Majalatitihad Al-Jamiat Al-Arabiyah, Jordan.

Alsharee, B. (2005). The role of the university in the knowledge industry: Reality and future (pp. 202-235). General Sixth Annual Conference in Management-creativity and innovation for human development - The role of Arab administration in the management of the knowledge society: Workshop business incubators, Egypt.

Alzoubi, Y. H. (2005). The university environment and its impact on stimulating and nurturing talent: the experience of the Philadelphia Jordanian University (Vol. 1, pp. 319-334). Fourth Arab Scientific Conference for the Gifted and Talented - Together to support talented and creative in a rapidly changing world. The Arab Council for the gifted and talented, Jordan.

Badran, S. (2007). The need for the development of creativity in the Arab higher education (Year 24, No. 77, pp. 5-49). Atarbiyah Al-Moasira, Egypt.

Baillie, C. (2010). Enhancing students' creativity through creative thinking techniques. Queens University, Ontario, Canada. Retrieved from http://www.news.uwa.edu.au/ 201004142392/issue-6-15-april-2010/learning-space-enhancing-students-creativity-through-c reative-thi

Barsons, T. (1971). The Institutionalization of Scientific Investigation. In B. Barber (Ed.), Sociology of Science.

Bulghath, S. (2006). The role of Arab universities in supporting the culture of creative scientific research (Vol. 127, pp. 124-139). Shoon Arabiyah, Egypt.

Chung, J. (1991). Collaborative learning strategies: The design of instructional environments for the emerging new school. Educational Technology, 31(6), 15-22.

Eways, S. M. (1996). Creativity in creating an environment of creativity in the university (pp. 1-15). Fifteenth annual scientific conference of the association of modern education, 
creativity in education and culture, Egypt.

Fisher, R. (1990). Teaching children to think. Blackwell, U.K.

Hasan, R. (2004). Creativity and inhibitors of the Egyptian university students - A field study on the University of Zagazig (Year 21, No. 66, pp. 79-164). Atarbiyah Al-Moasira, Egypt.

Hassan, Mohammed, et al. (1998). Foundations of Education. Dar Alkitab Aljamiei, UAE.

Hijazi, S. (2001). The psychology of creativity, definition, development and measured in children. Dar Alfikr Alarabi, Cairo.

Ibrahim, M. A. (2008). Cognitive creative thinking management and activating the role of scientific research, as two objectives of the Arab Universities'objectives (pp. 172-181). XV Annual National Conference - Towards a strategic plan for Arab university education, Egypt.

Jackson, N. (2008). Tackling the Wicked Problem of Creativity in Higher Education. Background paper for a presentation at the ARC Centre for the Creative Industries and Innovation, International Conference Brisbane, June, 2008. Retrieved from http://normanjackson.pbwiki.com/2008

Jackson, N. (2015). Developing Creativity through Life wide Education. Retrieved from http://www.normanjackson.co.uk/creativity.html

Jerio, D. H. (1988). Higher education in the Arab World - A future perspective (No. 23, pp. 146-152). Majallat Aittihad Aljamieat Alearabia, Jordan.

Jonassan, D. (1994). Thinking technology toward a Constructivist Design Model. Educational Technology, 34(4), 34-37.

Maayah, A. S. (2008). International experiences about the partnership between universities and production and services sectors (pp. 149-194). Conference partnership between the public and private sectors. Arab Organization for Administrative Development, Jordan.

Mahjoub, M. A. (2014). University learning source centers and their roles in the educational process and research from the viewpoint of the faculty members in the College of Education, University of Aldawadmi, KSA (pp. 279-307). First international conference titled libraries and information centers in a changing digital environment, Jordanian libraries and information, Jordan.

McRobbie, C. J., \& Fraser, B. J. (1993). Associations between student outcomes and psychosocial environment. Journal of Educational Research, 8(2), 78-85. http://dx.doi.org/10.1080/00220671.1993.9941170

Mechling, M., \& Oliver, R. (1983). Early adolescence: Integrating activities into a textbook program, science and children.

Mohamed, S. Z. (2013). Scientific creativity incubators in Egyptian universities in the light of the requirements of the knowledge economy - A proposed vision. Arabic Studies in Psychology \& Education, 3(41), 49-85. 
Mohammed, L. (2004). The role of university education in the activation of the creativity of scientific research students in the Faculties of Arts (Vol. 2, pp. 262-279). XI annual national conference. Arab university education, the prospects of reform and development, Egypt.

Mousa, F., \& Al Mariee, M. (2013). The development of scientific research in Saudi universities in the light of the knowledge society (Vol. 29, No. 4). Majallatkulliyat Altarbiyah, Faculty of Education, Assiut University.

Noor, K. (1998). The role of the professor in stimulating innovation and development (No. 33, pp. 313-340). Majallataittihadaljamieatalarabia, Jordan.

Obaid, W. (2004). University and creativity (Vol. 1, pp. 580-596). XI annual national conference. Arab university education, the prospects of reform and development, Egypt.

Qutb, S. (2006). The reality and constraints of student activities at Taibah University in Madinah, a field study (Vol. 12, pp. 97-262). Mustaqbal Alttarbia Alarabia, Egypt.

Ricardo, T. (2003). The physics laboratory, a historical overview and future perspectives. Science \& Education, 21(7).

Sabo, D. (1993). The organizational environment, health, and quality of student life in middle schools (Unpublished ed.). D. State University of New Jersey, USA.

Saleh, H. (2006). An analytical study of the partnership between the university and the community in light of the experiences of some countries (Master Degree Dissertation, Banha University, Egypt).

Shehata, H. (1992). School activities-concept, functions and applications (2nd ed.). Alddar Almisria Allubnania. Cairo.

Soliman, A. (2001). A recentinternational experiences in the gifted people (pp. 1-20). First forum for gifted institutions in Arab Gulf Countries, KSA.

Stuart, J. (1997). Design of the new library and learning sources center for the University of Paisley. New Library World, 98(4), 132-140. http://dx.doi.org/10.1108/03074809710168529

Tawfiq, A. (2005). Towards an Arab strategy to achieve excellence and innovation in higher education (pp. 52-69). Tenth conference of ministers and officials for higher education Excellence and innovation in higher education.

Wisconsin Department of Commerce. (2003). Wisconsin business incubators. Retrieved November 18, 2003, from http://www.commerce.state.wi.us

Ying, W. (2008). Learning physics in a Taiwanese college classroom: A constructivist perspective ( $\mathrm{PhD}$ thesis, Curtin University of Technology, Science and Mathematics Education Centre). Retrieved from http://espace.library.curtin.edu.au:80/R?func $=\mathrm{d}$ bin-jump-full\&local_base $=$ gen01-era02\&object_id $=129383$ 


\section{Copyright Disclaimer}

Copyright for this article is retained by the author(s), with first publication rights granted to the journal.

This is an open-access article distributed under the terms and conditions of the Creative Commons Attribution license (http://creativecommons.org/licenses/by/3.0/). 